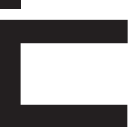

平牙止

ER(E

CIENTÍFICAS

EXATAS E TECNOLÓGICAS

ISSN IMPRESSO - 2359-4934

E-ISSN - 2359-4942

DOI - 10.17564/2359-4934.2016v2n2p37-46

\title{
SUSTENTABILIDADE: A CONSTRUÇÃO DO DISCURSO
}

Daniela Venceslau Bitencourt ${ }^{1}$

\section{RESUMO}

Para compreender a construção do discurso sobre sustentabilidade, o presente artigo tem como escopo a relevância de se colocar na ordem do dia as temáticas, bem como as práticas necessárias que assegurem os ensinamentos epistemológicos sobre sustentabilidade e discurso. A partir deles, buscamos apreender a construção; considerando a questão temporal, as variantes tecnológicas, os fatores políticos, econômicos e sociais.
Katia Santana Bispo²

\section{PALAVRAS CHAVE}

Sustentabilidade. Discurso. Conceito. 


\section{RESUMEN}

Para entender la construcción del discurso sobre la sostenibilidad, este documento tiene como escopo, la relevancia de incluirse en la agenda de los temas, asi como las prácticas necesarias para garantizar las enseñanzas epistemológicas sobre la sostenibilidad y discurso. Desde ellos, tratamos de captar la construcción; teniendo en cuenta la cuestión temporal, variantes tecnológicas, los factores políticos, económicos y sociales.

\section{ABSTRACT}

To understand the construction of discourse about sustainability, this article has as scope, the relevance of putting on the agenda the themes, as well practices required to ensure the teachings epistemological on sustainability and speech. From them, we seek to understand the construction; whereas the question, temporal variations in technology, the political, economic and social.

\section{PALABRAS CLAVE}

Sostenibilidad. Discurso. Concepto.

\section{KEYWORDS}

Sustainability. Speech. Concept. 


\section{INTRODUÇ̄̃̃O}

Há muito o discurso da sustentabilidade deixou, apenas, de buscar responder as demandas apresentadas pelos movimentos ambientalistas em suas diversas expressões. A necessidade de incluir a questão ambiental na agenda de prioridades tem sido entendida não só pelo mundo acadêmico, mas também, pela mídia e pela sociedade, sobretudo, pela indigência de se instituir mudanças de hábito que perpassam os limites da educação e se esteiam na sobrevivência de uma nova ordem político-econômico-social.

A discussão saiu dos limites do "ecologicamente sustentável” para o “politicamente correto” e necessário. É nesse contexto que elementos como educação ambiental e sustentabilidade passam a nortear a questão discursiva e trazem à baila fatores sociais que tendem a determinar o eixo discursivo e as interferências nele provocadas pelo intradiscurso e pelo interdiscurso.

Deste modo, tendemos a condicionar o nosso comportamento, sobretudo as nossas práticas histórico-culturais, a uma vivência pautada pelas exigências que o mundo nos impõe, especialmente, no que se refere à formação e à transformação do meio.

Assim, a abordagem deve sair do campo meramente técnico. É fundamental ampliar e incorporar a ela uma visão de futuro, criando uma perspectiva capaz de apontar os problemas ambientais que são tratados a miúde, colocando-os à prova da modernização ecológica e da nova exigência do mundo.

\section{REFERENCIAL TEÓRICO}

\subsection{DISCURSO}

A análise do discurso e o poder da palavra por intermédio de diversos autores, como Charaudeau,
Pêcheux, dentre outros, demonstram que, o discurso aplicado de forma correta, remete a construção e a aceitação pela massa envolvida pela mensagem. É o processo dinâmico da língua que permite inventar novos conceitos e, por conseguinte refazer a língua. Para Beveniste (1974, p. 24), “o poder de ação, de transformação, de adaptação, que é a chave da relação humana entre a língua e a cultura, uma relação de integração necessária”.

É pertinente entender que a cada época e contexto, corresponde um determinado tipo de formação ideológica. Nesta perspectiva, há que se destacar que um sujeito ocupando um lugar é dominado por uma determinada formação ideológica que preestabelece as possibilidades de sentido de seu discurso.

\section{Segundo Marilena Chauí (2006, p. 108):}

\begin{abstract}
[...] Ideologia representa um conjunto de ideias, pensamentos, doutrinas e visões de mundo de um indivíduo ou de um grupo, orientado para suas ações sociais e, principalmente, políticas. É um conjunto lógico, sistemático e coerente de representações (ideias e valores) e de normas ou regras (de conduta) que indicam ou prescrevem aos membros da sociedade o que devem pensar, o que devem valorizar e como devem valorizar, o que devem sentir e como devem sentir, o que devem fazer e como devem fazer.
\end{abstract}

No entendimento de Bakhtin (2002), pela linguagem se propagam as ideologias, fomentando conceitos e aceitações muitas vezes adversas ao entendimento do interlocutor. Para o autor, a ideologia do cotidiano constitui o domínio da palavra interior e exterior, de forma desordenada e não fixada num sistema, que acompanha cada um dos nossos atos ou gestos e cada um dos nossos estados de consciência.

É pertinente considerar que a linguagem é o instrumento que o homem usa para estabelecer relações, interagindo socialmente como forma de ação 
entre os interlocutores. Isso significa dizer que a linguagem é, portanto, dotada de intencionalidade que visa influenciar o comportamento do interlocutor, modificando suas convicções e ideias preconcebidas.

O avanço dos estudos linguísticos aponta a impossibilidade de dissociar da lingua a atividade do falante, mas é somente com o advento da linguística da enunciação que a linguagem deixa de ser vista apenas como instrumento externo de comunicação e de transmissão de informação para ser vista como uma forma de atividade entre os protagonistas do discurso, que se constitui uma unidade pragmática, capaz de produzir efeitos e reações.

\section{Conforme nos ensina Koch (2000, p. 21)}

[...] ao produzir um discurso, o homem se apropria da língua, não só com o fim de veicular mensagens, mas, principalmente, com o objetivo de atuar, de interagir socialmente, instituindo-se como 'eu' e constituindo, ao mesmo tempo, o outro que é por sua vez, constitutivo do própio 'eu'.

Assim, podemos afirmar que o discurso é um processo contínuo que não se esgota em uma situação particular do processo de comunicação. Dessa forma, a Análise do Discurso procura compreender a língua, fazendo sentido, concebe a linguagem como mediação necessária entre o homem e sua realidade natural e social. A Análise do Discurso privilegia a interpretação dos enunciados produzidos, isto é, coloca a interpretação como ponto central de discussão. Como diz Orlandi (2001, p. 21) “a Análise do Discurso visa a compreensão de como um objeto simbólico produz sentidos, como ele está investido de significância para e por sujeitos".

A partir das conferências, tratados e reuniões na área ambiental, podemos verificar o discurso da sustentabilidade, em primeiro lugar, como forma de gerenciar a reprodução econômica do capitalismo ante os efeitos da degradação ambiental. O conceito de discurso como expressão e exercício de poder pres- supõe a sustentabilidade como um campo discursivo onde uma pluralidade de forças e interpretações disputa entre si o reconhecimento como "o discurso verdadeiro" sobre o assunto.

Embora a sustentabilidade presuma como campo, um substrato comum identificado com a ideia de um "futuro viável" para as relações entre a sociedade e a natureza, esta base comum é muito vaga e permite leituras diversas sobre o que significa um futuro viável e sobre quais os melhores meios de alcançá-lo.

Assim, à medida que o debate da sustentabilidade vai se tornando mais complexo e é difundido socialmente, ele vai sendo apropriado por diferentes forças sociais que passam a lhe imprimir o significado que melhor expressa seus valores e interesses particulares. Viola e Oliveira (1997) reafirmam, analisando o cenário do ambientalismo contemporâneo, as ideias de diversidade e conflito.

\subsection{SUSTENTABILIDADE: A CONSTRUCC̄̃O DE UM CONCEITO}

O conceito de desenvolvimento sustentável provém de um relativo longo processo histórico de reavaliação crítica da relação existente entre a sociedade civil e seu meio natural. Por se tratar de um processo continuo e complexo, observa-se a existência de uma variedade de abordagens que procura explicar o conceito de sustentabilidade.

Segundo Leff (2004, p. 15), o princípio da sustentabilidade surge,

[...] No contexto da globalização como a marca de um limite e o sinal que reorienta o processo civilizatório da humanidade. A crise ambiental veio questionar a racionalidade e os paradigmas teóricos que impulsionaram e legitimaram o crescimento de econômico, negando a natureza. A sustentabilidade ecológica aparece assim como um critério normativo para a reconstrução da ordem econômica, como uma condição para a sobrevivência humana e um suporte para chegar a um desenvolvimento duradouro, questionando as próprias bases da produção. 
Segundo Camargo (2003), o termo desenvolvimento sustentável foi primeiramente divulgado por Robert Allen no artigo "como salvar o mundo", lançado conjuntamente pela União Mundial para a Conservação da Natureza (UICN), pelo fundo para a vida selvagem (WWF). 0 foco do conceito é a integridade ambiental e apenas a partir da definição do relatório Brundtland a ênfase desloca-se para o elemento humano, gerando um equilíbrio entre as dimensões econômica, ambiental e social.

Para Goldsmith (1972), uma sociedade pode ser considerada sustentável quando todos os seus propósitos e intenções podem ser atendidos indefinidamente, fornecendo satisfação ótima para seus membros. Neste sentido, carece a efetivação de políticas públicas e de ações que leve o indivíduo a pensar e atuar de forma politicamente correta e ecologicamente sustentável, de modo a garantir a preservação dos recursos naturais finitos.

O conceito de desenvolvimento sustentável deve ser inserido na relação dinâmica entre o sistema econômico humano e um sistema maior, com taxa de mudança mais lenta, o ecológico. Para ser sustentável, diz Van Bellen (2006, p. 24),

[...] Essa relação deve assegurar que a vida humana possa continuar indefinidamente, com crescimento e desenvolvimento da sua cultura, observando-se que os efeitos das atividades humanas permaneçam dentro de fronteiras adequadas, de modo a não destruir a diversidade, a complexidade e as funções do sistema ecológico de suporte à vida.

Desse modo, sustentar significa segurar, suportar, apoiar, resistir, conservar, manter, dentre outros. Segundo Brügger (1994), na expressão desenvolvimento sustentável a palavra sustentável costuma adquirir um sentido mais especifico, remontando aos conceitos de ecologia, referindo-se, de modo geral, à natureza homeostática dos ecossistemas naturais e à autoperpetuação sustentável, nesse sentido englobaria a ideia de capacidade de suporte ao qual se refere ao binômio recursos-população. Brügger (1994) ressalta, ainda, que o adjetivo "sustentável" adicionado a "desenvolvimento" tem guardado uma dimensão técnica e naturalista, provavelmente adequada para lidar com populações animais e vegetais, mas insuficiente para dar conta da complexidade que envolve as relações homem-natureza.

Conforme Herculano (1994), apesar da percepção de desenvolvimento como uma questão política e social, a concepção do termo que predomina e persiste é de que o desenvolvimento e crescimento dos meios de produção têm a ver com inovação técnica, expansão das forças produtivas, e não com alteração das relações sociais de produção.

Nessa perspectiva, constrói-se um entendimento de sustentabilidade que se volta para o novo. Essa noção é calcada em novos paradigmas que possam, de fato, consubstanciar uma nova relação do ser humano com ele mesmo e dele com a natureza, constituindo-se, segundo Guimarães (2003), nos "três pilares dessa nova proposta: a eficiência econômica, a justiça social e a prudência ecológica”.

A sedimentação desta nova concepção de sustentabilidade, no entanto, é fruto de uma transformação nos paradigmas epistemológicos que estão no alicerce da ciência ambiental. Em outras palavras, após o advento da mecânica quântica, a ideia de complexidade, ligada à interconectividade inerente aos processos sistêmicos, a incerteza advinda da teoria desenvolvida por Heisenberg e o indeterminismo, entre outros fatores, trouxeram um novo patamar de compreensão da realidade.

Como se pode observar, apesar dos conflitos gerados pelo uso da nomenclatura, o termo desenvolvimento sustentável é claramente carregado de valores, estando intimamente ligado a princípios como a ética, as crenças e os valores que fundamentam uma sociedade ou comunidade e sua concepção de sustentabilidade. Dahl (1997) pondera que um dos problemas do 
conceito refere-se ao fato de que a sociedade deve saber para onde quer ir para que depois se possa medir se esses objetivos ou direção estão sendo alcançados.

0 conceito de sustentabilidade envolve a questão temporal, pois a sustentabilidade de um sistema só pode ser observada a partir da perspectiva futura, de ameaças e oportunidades. Todavia, as ameaças para a viabilidade do sistema, segundo Bossel (1999), derivam de alguns fatores: as dinâmicas da tecnologia, da economia e da população.

Todos podem levar a uma acelerada taxa de mudanças. A necessidade de operacionalizar o conceito de sustentabilidade, que julga estar implícito na sociedade, acreditando na improbabilidade desse sistema ter uma tendência à autodestruição. Afirma Van Bellen (2006, p. 28):

[...] Que a operacionalização deve auxiliar na verificação sobre a sustentabilidade ou não do sistema, ou pelo menos ajudar na identificação das ameaças à sustentabilidade de um sistema. Para isso há a necessidade de se desenvolver indicadores que forneçam essas informações sobre onde se encontra a sociedade em relação à sustentabilidade.

Em termos gerais, para Hardi e Zdan (1997), a ideia de sustentabilidade está ligada à persistência de certas características necessárias e desejáveis de pessoas, suas comunidades e organizações, e os ecossistemas que as envolvem, dentro de um período de tempo longo ou indefinido. Para atingir o progresso em direção à sustentabilidade deve-se alcançar o bem-estar humano e dos ecossistemas, sendo que o progresso em cada uma das esferas não deve ser alcançado à custa da outra. Na verdade, há uma interdependência entre os dois sistemas.

Contudo, esta operacionalização emerge como o grande desafio civilizatório, principalmente quando se pensa de que modo é concretizada a sustentabilidade num contexto social hegemonizado pelo mercado. Enfatiza Lima (2002, p. 122) que "o atual debate teórico-político e a própria leitura da relação atual entre mercado e (in)sustentabilidade apresentam argumentos expressivos para demonstrar a inviabilidade de as forças de mercado serem capazes de realizar uma sustentabilidade".

O século $X X$, portanto, foi testemunha de transformações significativas em todas as dimensões da existência humana. Ao lado do exponencial desenvolvimento tecnológico, que aumenta a expectativa de vida dos seres humanos e ao mesmo tempo sua capacidade de autodestruição, ocorreu um crescimento significativo da utilização de matéria e energia para atender as necessidades da sociedade.

Esse contexto faz com que o relacionamento entre homem e natureza passe por profundas transformações, principalmente na percepção que esse tinha da natureza e dos problemas ambientais. Diz Camargo (2003, p. 43), "o despertar das recentes gerações em direção a valores ecológicos tem sido denominado de várias maneiras, tais como: conscientização ecológica ou ambiental, percepção ecológica ou ambiental, sensibilização ecológica ou ambiental".

Jamais alguma civilização teve em âmbito planetário o poder destruidor que tem a sociedade contemporânea. Segundo a Agenda 21 (1995), a humanidade encontra-se em um momento de definição histórica. Para Capra (1982), estamos chegando a um momento decisivo como indivíduos, como sociedade e como civilização.

Segundo Drew (1989), o homem é hoje o mais poderoso agente das alterações das condições na superfície terrestre. $O$ século $X X$ testemunhou o surgimento de uma nova e importante tarefa: proteger a natureza do ser humano. Os problemas ambientais com que os indivíduos se defrontam não são novos, embora só recentemente sua complexidade começa a ser compreendida. Conforme assegura Capra (1996), quanto mais se estuda os principais problemas de nossa época, mas se é levado a perceber que eles não podem 
ser entendidos isoladamente, sendo problemas sistêmicos, interligados e interdependentes.

Na visão de Soffiat (2002), crises ambientais de raízes antrópicas não constituem novidade na história da humanidade, mas a singularidade da atual crise ambiental aparece exatamente na combinação de seu caráter antrópico com sua extensão planetária. A crise generaliza-se com tal velocidade e com tal dimensão que não basta buscar suas causas só na desestruturação dos sistemas naturais que sustentam a vida.

Se a década de 1950 marca a preocupação ecológica na comunidade científica, a década de 1960 marca este processo relacionado aos atores do sistema social. Segundo Porto Gonçalves (1996), a década de 1960 assistiu ao crescimento de movimentos que criticavam não só os modos de produção, mas também os de vida. Diversos grupos e organizações não-governamentais começam a aparecer e a crescer neste período, como é o caso da World Wildlife Fund (atual World Wide Fund for Nature - WWF), primeira ONG ambiental de espectro verdadeiramente mundial.

A década de 1970 destaca-se para criação de diversas organizações internacionais que visavam a discutir os problemas ambientais em âmbito mundial; dos primeiros movimentos ambientalistas e a absorção da preocupação ambiental pelo sistema político - governos e partidos.

A década de 1980, por sua vez, destaca-se pelo surgimento, em grande parte dos países, leis regulamentando a atividade industrial no que se refere à poluição. Complementa Camargo (2003, p. 51),

[...] também na década de 1980 houve um grande impulso quanto a formalismo na realização de estudos de impacto ambiental e relatórios de impacto ambiental (EIA/Rima), com audiências publicas e aprovações em diferentes níveis de organizações do governo.

A década de 1990 caracteriza-se pelo grande impulso que a consciência ambiental teve na maioria dos países do globo. Segundo Moura (2000), o termo "qualidade ambiental" passou a fazer parte do universo social. Destaca-se neste período a realização da Conferencia das Nações Unidas Sobre o Meio Ambiente e Desenvolvimento, conhecida como Rio-92, Eco-92 ou Cúpula da Terra. Para Franco (2000), ficou evidente que a humanidade havia chegado a um momento de definição de sua história: ou ficar com o modelo político vigente ou mudar o rumo, melhorando a qualidade de vida dos pobres e protegendo o meio ambiente, para alcançar um futuro melhor.

Em março de 2000, fora aprovada a carta da Terra que apresentada e assumida pela Organização das Nações Unidas (ONU) em 2002, baseada em princípios e valores fundamentais, ela serve como código ético planetário, sendo equivalente à Declaração dos Direitos Humanos no que concerne à sustentabilidade, à equidade e à justiça. Assim se a consciência ambiental cresceu consideravelmente a partir da segunda metade do século $X X$, estabelecendo novos parâmetros na relação homem/natureza, a percepção dos problemas ambientais ocorreu de modo diferenciado ao longo do tempo. Para Camargo (2003, p. 61):

\begin{abstract}
[...] Numa primeira etapa, ocorreu a percepção dos problemas ambientais localizados. Numa segunda etapa, a degradação ambiental é percebida como um problema generalizado, porém confinado nos limites territoriais dos Estados Nacionais. Numa terceira etapa, a degradação ambiental é percebida como um problema planetário e que atinge a todos.
\end{abstract}

No entanto, o Brasil sediou uma grande reunião mundial, a Rio+20, evento que marcou os 20 anos da emblemática Cúpula da Terra, também realizada no Rio de Janeiro, em 1992, e os 40 anos depois da primeira reunião mundial sobre o tema, em Estocolmo.

O objetivo da Rio+20 foi estimular novas medidas rumo a uma "economia verde" e estimular os indivíduos à preservação e ao consumo consciente de bens imprescindíveis, como a água, a alimentação e a energia sem comprometer as gerações futuras. 0 evento chamou a 
atenção de todo o planeta para a necessidade de se implementar uma gestão sustentável desses recursos.

É neste panorama que emergem discussões sobre desenvolvimento e sustentabilidade na estruturação de mecanismos que possam criar uma relação harmônica entre homem/natureza na construção de um mundo mais justo onde o bem-estar social, a qualidade de vida, a equidade, o meio ambiente e a justiça ergam-se como pilares reais da vida das pessoas.

\section{CONCLUSÃO}

Uma análise do mundo atual nos leva a uma situação de releitura e, consequentemente, de percepção sobre o papel da sociedade como um todo, considerando os seus valores, princípios éticos e morais. Ao nos debruçarmos sobre os mais variados conceitos, observamos e concordamos que a sustentabilidade só pode ser pensada a partir de uma perspectiva futura de ameaças e oportunidades. Precisamos enxergar o contexto na qual essa peça da sustentabilidade está inserida para entendermos quais os impactos (positivos e negativos) que ela provocará ao meio, de forma particular, ao ambiental.

Devemos considerar que nem todo avanço, representa destruição natural. Ele pode resultar em desenvolvimento sustentável, gerando novas dinâmicas sociais e abrindo perspectivas, sobretudo, econômica para a população. Constatamos que todos podem ganhar e essas mudanças de paradigmas do que é sustentável pode, sim, apontar para uma acelerada mudança econômica e social.

O ideal seria que o desenvolvimento pudesse vir aliado ao senso de justiça e oportunidades para todos os seres humanos do planeta, sem privilégio de algumas espécies, sem destruir os recursos naturais finitos e sem ultrapassar a capacidade de carga do sistema. Isso, porém, perpassam os limites do homem que apesar da inegável ajuda da tecnologia, ainda, não consegue pautar as suas condutas em ações totalmente equilibradas e igualmente favoráveis e a todos os setores da sociedade civil organizada.

\section{REFERENCIAS}

\section{BAKHTIN, Mikhail. Marxismo e filosofia da}

linguagem. São Paulo: Hucitec/Anna Blume, 2002.

\section{BEVENISTE, Émile. Problemas de linguística geral \\ II. Campinas-SP: Pontes Editores, 1974.}

\section{BOSSEL, H. Indicators for Sustainable}

Development: Theory, Method, Applications: a report to the Balaton Group. Winnipeg: IISD, 1999

\section{BRUGGER, Paula. Educação ou adestramento}

ambiental. Coleção teses. Letras contemporâneas. Itha de Santa Catarina, 1994. 141p.

CAPRA, Fritjof. A teia da vida: Uma nova compreensão cientifica dos sistemas vivos. São Paulo: Cultrix, 1996.

CHARAUDEAU, Patrick. Discurso político. Tradução Fabiana Komesu e Dílson Ferreira da Cruz. São Paulo: Contexto, 2006.

CHARAUDEAU, Patrick. Discurso político. São Paulo: Contexto, 2008.

CHAUI, Marilena. 0 que é ideologia. 2.ed. São Paulo: Brasiliense, 2006.

CAMARGO, A.L.B. Sustentabilidade - entraves globais e reflexões. In: Desenvolvimento sustentável - dimensões e desafios. Campinas: Papirus, 2003. p.113-124.

CAMARGO, L.H.R. O Novo Paradigma. In: A ruptura do meio ambiente. Rio de Janeiro: Bertrand Brasil, 2005. p.51-78. 
DAHL, Robert. Poliarquia, participação e oposição. São Paulo: Eduesp, 1997.

\section{DREW, D. Processos interativos homem-meio}

ambiente. 2.ed. Rio de Janeiro: Bertrand Brasil, 1989.

FRANCO, Maria de Assunção Ribeiro. Planejamento ambiental para a cidade sustentável. São Paulo: Annablume, 2000.

GOLDSMITH, Edward Robert Allen et al. (Ed.). A blueprint for survival. The Ecologist. London: Penguin Books, v.2, n.1, jan. 1972. Disponível em: <http://www. theecologist.info>. Acesso em: fev. 2014.

\section{GONÇALVES, C.W.P. Os (dês) caminhos do meio} ambiente. São Paulo: Contexto, 1989.

GUIMARÃES, M. Sustentabilidade e Educação Ambiental. In: CUNHA, S.B. e GUERRA, A.J.T. (Org.). A questão ambiental - diferentes abordagens. Rio de Janeiro: Bertrand Brasil, 2003. p.81-105.

\section{HERCULANO, S.C. Entre o Heroísmo e a}

Cidadania (O Fórum Brasileiro de ONGs e Movimentos Sociais para o Meio Ambiente e o Desenvolvimento, a Sociedade Civil e o Estado: um estudo de caso sobre o exercício da cidadania pelos segmentos intelectualizados das classes médias). 1994. Tese (Doutorado) - IUPERJ, Rio de Janeiro, 1994.

\section{HARDI, P.; ZDAN, T. (Eds). Assessing sustainable development: principles in practice. Canada: International Institute for Sustainable Development, 1997.}

JOHNSTON, J. Métodos econométricos. São Paulo: Atlas, 1971.

$\mathrm{KOCH}$, Ingedore Villaça. Argumentação e linguagem. São Paulo: Cortez, 2000.
LEFF, Enrique. Saber Ambiental: sustentabilidade, racionalidade, complexidade, poder. 3.ed. Petrópolis: Vozes, 2004.

LIMA, Gustavo Ferreira da Costa. Crise ambiental, educação e cidadania: os desafios da sustentabilidade emancipatória. In: LAYRARGUES, Philippe Pomier; Castro, Ronaldo de Souza; LOUREIRO, Carlos Frederico Bernardo (Org.). Educação ambiental: repensando o espaço da cidadania. São Paulo: Cortez, 2002.

MAINGENEAU, Dominique. Novas tendências em análise do discurso. Trad. Freda Indursky. Campinas: Pontes, 1997.

\section{MAINGENEAU, Dominique. Análise de textos de comunicação. São Paulo: Cortez, 2001.}

ORLANDI, Eni Puccinelli. Discurso e texto: formação e circulação dos sentidos. Campinas-SP: Pontes, 2001.

PORTO-GONÇALVES, C.W. 0 desafio ambiental. Rio de Janeiro: Record, 2004. p.13-75.

SOFFIATI, A. Fundamentos filosóficos e históricos para o exercício da ecocidadania e da ecoeducação. In: LOUREIRO, C.F.B.; LAYRARGUES, P.P.; CASTRO, R.S. de, (Org.). Educação ambiental: repensando o espaço da cidadania. São Paulo: Cortez, 2002.

VAN BELLEN, H.M. Indicadores de sustentabilidade: uma análise comparativa. 2.ed. Rio de Janeiro: Fundação Getúlio Vargas, 2006

VIOLA, Eduardo; OLIVEIRA, Alejandro. Globalização, sustentabilidade e governabilidade democrática no Brasil. In: TRINDADE, Antônio Cançado; CASTRO, Marcus Faro de (Org.). A sociedade democrática no final do século. Brasília: Paralelo 15, 1997. p.179-254. 
1. Pesquisadora CNPO/FAPITEC/UFS; Graduada em Administração pela Faculdade de Negócios de Sergipe - FANESE; Mestre e Doutora pelo Programa de Pós-Graduação em Desenvolvimento e Meio Ambiente pela Universidade Federal de Sergipe - PRODEMA/UFS. E-mail: daniela.aju@hotmail.com se7comunicacao.com.br 